\title{
Single-phase friction riveting: metallic rivet deformation, temperature evolution, and joint mechanical performance
}

\author{
Gonçalo Pina Cipriano ${ }^{1,2} \cdot$ Aakash Ahiya $^{3}$. Jorge F. dos Santos ${ }^{3} \cdot$ Pedro Vilaça $^{2}$ - Sergio T. Amancio-Filho ${ }^{1}$
}

Received: 3 May 2019 / Accepted: 9 September 2019 / Published online: 5 November 2019

(C) The Author(s) 2019

\begin{abstract}
The present work explores the feasibility of single-phase friction riveting on unreinforced thermoplastics. In single phase, the load is kept constant throughout the process, avoiding the forging phase with higher axial force, used in the conventional process. This process variant can constitute an answer when payload restrictions exist. The results demonstrate the feasibility of singlephase friction riveting on unreinforced polyetherimide plates joined by AA2024 rivets with $5 \mathrm{~mm}$ of diameter. A Box-Behnken design of experiments and analysis of variance were used to set parameter matrix and understand the correlations between parameters and joint properties. A large variation of the mechanical energy input was observed (151-529 J). Overdeformation and material rupture were observed in higher energy conditions. Lower energy input yielded a bell-shaped rivet plastic deformation, corresponding to the best performance. The maximum process temperatures varied between 461 and $509^{\circ} \mathrm{C}$. This friction riveting process variant allowed a considerable high mechanical strength to be achieved, with ultimate tensile force of $7486 \mathrm{~N}$, comparable with the two-phase friction riveting process, albeit applying lower axial forces, such as $2400 \mathrm{~N}$. Within the investigated conditions, this study proves the feasibility of the single-phase process, achieving good global mechanical performance and energetically efficient conditions, without forging phase.
\end{abstract}

Keywords Plastics $\cdot$ Aluminum $\cdot$ Hybrid $\cdot$ Joining $\cdot$ Friction $\cdot$ Riveting

\section{Introduction}

In recent years, several industries, such as transport, have been introducing less conventional solutions to their designs. These having as main goals, leaner production processes which result in more cost-effective products and having these products meet increasing concerns and stricter regulations, during their

Recommended for publication by Commission III - Resistance Welding, Solid State Welding, and Allied Joining Process

Gonçalo Pina Cipriano

goncalo.pinacipriano@tugraz.at

1 Institute of Materials Science, Joining and Forming, BMVIT Endowed Professorship for Aviation, Graz University of Technology, 8010 Graz, Austria

2 Department of Mechanical Engineering, School of Engineering, Aalto University, FI-02150 Espoo, Finland

3 Centre for Materials and Coastal Research, Institute of Materials Research, Materials Mechanics, Solid State Joining Process, Helmholtz-Zentrum Geesthacht, 21502 Geesthacht, Germany operation, regarding pollution and recyclability. With the introduction of multi-material hybrid solutions, alternative technologies, capable of joining such material combinations, became necessary.

Hybrid connections between nonweldable dissimilar materials have been traditionally performed by mechanical fastening, adhesive bonding, or combinations of both $[1,2]$. Both these technologies present drawbacks and design compromises. The need for added components in mechanical fastening leads to an increase in weight, and assembly procedures may become more complex, requiring access to both sides of a component [2,3]. In the case of adhesive bonding, production times and supply chains must take into account possibly long curing times involved [4]. Moreover, these connections are more susceptible to suffer degradation under adverse environmental conditions [4].

Several technologies capable of performing hybrid connections in alternative ways have been developed to tackle the limitations of conventional ones [5]. These aim for solutions to designs where evermore dissimilar connections are necessary to accommodate the usage of polymer and composites, where previously only metals were 
applied. Friction spot joining is one of these technologies. Capable of performing single lap joints between metal and polymer/composite, this technology can be a good alternative to conventional adhesive bonding. Goushegir et al. reported on the performance achieved by AA2024/carbonfiber-reinforced poly(phenylene sulfide) joints produced by friction spot joining [6]. Another technology developed with hybrid connections in mind allows hybridstaked joints to be performed. Abibe et al. have reported on this technology and on the mechanical behavior of connections between AA2024-T351 and polyamide 6/6 reinforced with $30 \%$ of short glass fiber [7]. Feistauer et al. [8] investigated the joining of Ti6Al4V parts, produced by metal injection molding, with glass-fiberreinforced polyetherimide, making use of surface profiles to promote mechanical interlocking, by ultrasonic vibration.

Friction riveting has been developed based on both mechanical fastening and friction welding principles, as a technology capable of establishing mechanical connections between dissimilar materials [9], namely metals and polymers/ composites. Several material combinations have been successfully joined with this process and the resulting mechanical properties evaluated, using rivets of AA6056-T6 [10], titanium grades 2 and 3 [11, 12], and Ti6Al4V [13]. Different joining configurations have also been accomplished, with multi-layer joints produced via direct-friction riveting process variant [14].

The present work aims at evaluating the possibility of joining AA2024-T351 with PEI by single-phase friction riveting, using force control and time limits, which until now had yet to be investigated. This process variant would not make use of a second phase after the initial friction one. Hence, it would avoid a considerable increase in the axial force that usually takes place during the forging phase. This would allow for lower equipment requirements without necessarily compromising the effectiveness of the joining process. The process temperatures and mechanical energy input were registered, and in-depth geometric analysis of the joints supports the investigation. The influence of process parameters on the main joint features were statistically determined, and the joints were mechanically quasi-statically tested to evaluate their global performance.

\section{Single-phase force-controlled friction riveting}

On its simplest configuration, friction riveting, as the name entails, is a friction-based mechanical fastening technique which allows a single featureless rivet to be joined with a single polymeric plate. Several process configurations have been successfully joined, with various overlapping material combinations (or multi-layered) [9]. Several joint configurations are possible, including metallic rivets with threaded profiles [9] and hollow rivets [15]. A metallic layer of substrate can also be included in the joint, depending on the metallic combination of materials and parameters used. The joint is produced by plastically deforming the rivet inside the substrate material (polymer/ composite). This plastic deformation of the rivet tip is achieved by the heat that is generated locally as the rotating rivet is pressed against the substrate. The increase of temperature at the tip of the rivet initially results from solid friction. Once the substrate material softens/melts, the heat generation can result from viscous dissipation due to internal shear in the molten polymeric material,
Fig. 1 Schematic representation of the single-phase friction riveting process: a sequence of the single friction phase from the initial configuration position until final consolidated joint condition; b parametric representation of the main geometric features of the joint, namely, $H$, rivet penetration depth; $W$, maximum width of the deformed rivet tip; Dp, anchoring depth; $B$, height of the deformed rivet tip a)
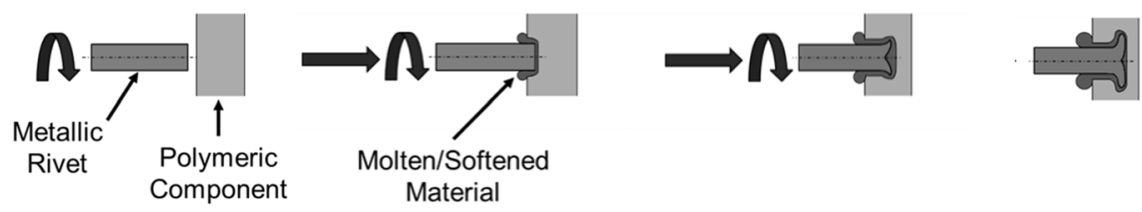

Initial Position

Rivet Insertion

Plastic Deformation

Consolidated Joint
Single-phase: the friction phase

b)

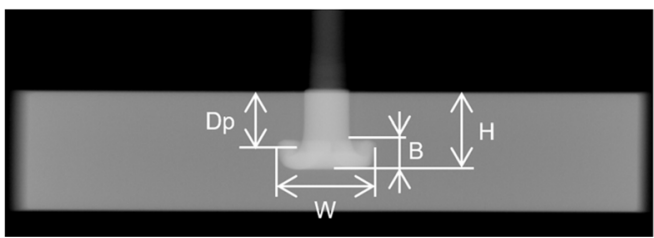


Table 1 Common nominal chemical composition for AA2024-T351 [19]

\begin{tabular}{llllllllll}
\hline Element & $\mathrm{Al}$ & $\mathrm{Cr}$ & $\mathrm{Cu}$ & $\mathrm{Fe}$ & $\mathrm{Mg}$ & $\mathrm{Mn}$ & $\mathrm{Si}$ & $\mathrm{Ti}$ & $\mathrm{Zn}$ \\
\hline Weight (wt\%) & $90.7-94.7$ & $\leq 0.10$ & $3.8-4.9$ & $\leq 0.50$ & $1.2-1.8$ & $0.3-0.9$ & $\leq 0.5$ & $\leq 0.15$ & $\leq 0.25$ \\
\hline
\end{tabular}

e.g., unreinforced thermoplastic substrate, from solid friction or a combination of the two [16]. Figure 1a illustrates the process phases used to perform single-phase friction riveting.

The force-controlled friction riveting has been used in such a manner that two process phases have been applied, friction and forging. The friction phase occurs while the rivet is rotating, characterized by three process parameters, rotational speed (RS), friction force (FF), and friction time (FT). After this friction phase, the rotation of the rivet is reduced to zero and a forging phase is applied to further plastically deform the rivet, achieving an axisymmetric deformation wider than the original rivet diameter. Two parameters are used in the forging phase, forging force (FoF) and forging time (FoT). Pina Cipriano et al. $[17,18]$ have investigated and discussed the contributions of both phases in their work. The forging phase is not used in this work, hence, using the single-phase (forcecontrolled) friction riveting terminology. Figure $1 \mathrm{~b}$ offers a representation of the plastic deformation underwent by the metallic rivet. Here, the final geometry of the rivet is assessed by performing several measurements on the inserted metallic rivet, as seen in the figure.

\section{Materials and methods}

\subsection{Base materials}

For the present work the materials used were AA2024-T351 (rivets) and polyetherimide (PEI). The metallic rivets used were produced from extruded aluminum. Having a plain cylindrical design with $60 \mathrm{~mm}$ in length and $5 \mathrm{~mm}$ in diameter. This alloy undergoes a solution heat treatment and stress relieving, applied by stretching (cold-worked). The mechanical composition of this alloy is presented in Table 1.

Table 2 Selected AA2024-T351 properties [20]

\begin{tabular}{ll}
\hline Property & Value \\
\hline$R_{0.2}(\mathrm{MPa})$ & 310 \\
$R_{m}(\mathrm{MPa})$ & 427 \\
$E(\mathrm{MPa})$ & 72 \\
Annealing temperature $\left({ }^{\circ} \mathrm{C}\right)$ & $518-548$ \\
Solution heat treatment temperature $\left({ }^{\circ} \mathrm{C}\right)$ & 495 \\
Melting temperature domain $\left({ }^{\circ} \mathrm{C}\right)$ & 256 \\
\hline
\end{tabular}

The mechanical properties of main interest for this alloy are shown in Table 2.

The polymeric plates used were produced from extruded PEI, with a final geometry of $70 \times 70 \mathrm{~mm}$ and a nominal thickness of $13.4 \mathrm{~mm}$. The extruded PEI was sourced from Quadrant Engineering Plastic Products, Lenzburg, Switzerland. This is an engineering thermoplastic developed by Wirth et al. [21]. Given its properties, such as its flame resistance, this thermoplastic is qualified to be used in automotive and aeronautic industries [22]. Some relevant properties of PEI are shown in Table 3.

\subsection{Joining procedure}

The hybrid metal-polymer joints were produced for the present work using a custom laboratory-scale equipment, RNA, by H. Loitz-Robotik, Hamburg, Germany. Although this equipment was designed with friction riveting in mind, there are commercially available solutions which would also be able to perform these types of joints, given the right parameter sets and type of process control. This friction riveting equipment has a spindle with a top rotational speed of $21 \mathrm{krpm}$ and is capable of applying $24 \mathrm{kN}$ of axial load. Live monitoring of position, force, and torque were used. The single-phase friction riveting process parameters used and their respective ranges are shown in Table 4.

\subsection{Energy input}

The mechanical energy input used to produce each of the investigated joints was determined using Eq. 1, following the same approach as Pina Cipriano et al. [17] and other authors working with friction riveting [24]. This has been applied for friction-based processes with both thermoplastic materials [25] and metals [26].

$E_{\mathrm{M}}=E_{\mathrm{f}}+E_{\mathrm{d}}=\int M \times \omega \times \mathrm{d} t+\int F \times \vartheta \times \mathrm{d} t[J]$

Table 3 Selected PEI properties [23]

\begin{tabular}{ll}
\hline Property & Value \\
\hline$R_{0.2}(\mathrm{MPa})$ & 129 \\
$E(\mathrm{MPa})$ & 3500 \\
Glass transition temperature $\left({ }^{\circ} \mathrm{C}\right)$ & 215 \\
Thermal conductivity $(\mathrm{W} /(\mathrm{m} * \mathrm{~K}))$ & 0.24 \\
\hline
\end{tabular}


Table 4 Process parameters and respective ranges

Parameters

\begin{tabular}{llll}
\cline { 2 - 3 } & Rotational speed (RS) & Friction force (FF) & Friction time (FT) \\
\hline Range & $19-20(\mathrm{krpm})$ & $2.4-2.8(\mathrm{~N})$ & $2.4-2.8(\mathrm{~s})$ \\
\hline
\end{tabular}

The frictional term $\left(E_{f}\right)$ results from the torque $(M)$ being applied and the rotational speed used $(\omega)$. Second term, deformational energy $\left(E_{d}\right)$ is dependent on the axially applied force $(F)$ and plunging rate $(\vartheta)$. In their work, Pina Cipriano et al. [17] calculated both the frictional and deformational terms of the equation. For the present work, only the friction component was used, since no forging phase was applied, and during the friction phase, the plunging speed is much lower than the rotation speed, resulting in a negligible contribution by the linear deformation (less than 4\% [24]) to the total mechanical energy input.

\subsection{Process temperature}

The process temperature measurements were performed using an infrared camera, captured via High-End Camera Series ImageIR, Infratech $\mathrm{GmbH}$, Dresden, Germany. This equipment was calibrated for measurements between 150 and $700{ }^{\circ} \mathrm{C}$. The lens was positioned at a distance of $500 \mathrm{~mm}$ with an approximately $19^{\circ}$ inclination angle, focusing on the rivetinsertion area.

\subsection{Design of experiments and statistical analysis}

A Box-Behnken design of experiments (DoE) was used in order to minimize the number of samples necessary, while achieving a considerable amount of results and information [27]. This design allows for a response surface methodology approach when evaluating the investigated responses [28]. It was considered necessary in order to achieve an understanding on how the process parameters could have cumulative effects, nonlinear, on joint formation. This would not be evaluated when using a lower order DoE. The RS, FF, and FT joining parameters were considered statistical input factors. The statically investigated process responses were rivet penetration $(H)$, maximum width of the deformed rivet tip $(W)$, process temperature, and mechanical energy input (Fig. 1b). The terms of the statistical models were obtained by a stepwise backward elimination procedure in order to determine the statistical regression models, sequentially eliminating the least significant parameters. These linear, two-way interaction and quadratic terms were only considered when being statistically significant, with an $\alpha$ (alpha) to remove of 0.05 and maintaining a principle of hierarchy $[27,28]$.
Table 5 shows the nonrandomized parameter matrix that resulted from the DoE. Additionally to the 12 runs of the second-order design with three parameters with three levels each (Table 4), five center points were used for pure error estimation.

\subsection{Mechanical performance}

The produced joints were mechanically tested to assess their global mechanical performance via quasi-static pull-out tensile testing. The procedure was similar to what has been reported in literature for friction riveted joints $[18,29]$ (adapted from ISO 6892 [30]). The equipment used was a 100-kN load cell Zwick/Roell 1478 universal testing machine, by Zwick/ Roell, Ulm, Germany. A free length of $22 \mathrm{~mm}\left(L_{0}\right)$ was used between the rivet constrained by the upper equipment grapple and the surface of the polymer. The constraints placed over the polymeric plate, used to hold the plate in-place, were set at a minimum radial distance of $40 \mathrm{~mm}$ from the center of the rivet.

\section{Results and discussion}

\subsection{Joint formation}

The plastic deformation underwent by the metallic rivet was assessed by joint formation measurements, which characterize

Table 5 Parameter matrix

\begin{tabular}{llll}
\hline Joining condition & \multicolumn{2}{l}{ Parameters } \\
\cline { 2 - 4 } & RS (rpm) & FF (N) & FT (s) \\
\hline 1 & 19,000 & 2400 & 2.6 \\
2 & 20,000 & 2400 & 2.6 \\
3 & 19,000 & 2800 & 2.6 \\
4 & 20,000 & 2800 & 2.6 \\
5 & 19,000 & 2600 & 2.4 \\
6 & 29,000 & 2600 & 2.4 \\
7 & 19,000 & 2600 & 2.8 \\
8 & 20,000 & 2600 & 2.8 \\
9 & 19,500 & 2400 & 2.4 \\
10 & 19,500 & 2800 & 2.4 \\
11 & 19,500 & 2400 & 2.8 \\
12 & 19,500 & 2800 & 2.8 \\
13 & 19,500 & 2600 & 2.6 \\
14 & 19,500 & 2600 & 2.6 \\
15 & 19,500 & 2600 & 2.6 \\
16 & 19,500 & 2600 & 2.6 \\
17 & 19,500 & 2600 & 2.6 \\
\hline
\end{tabular}


Table 6 Rivet joint formation measurements

\begin{tabular}{lllll}
\hline \multirow{2}{*}{ Joining condition } & \multicolumn{4}{l}{ Joint formation } \\
\cline { 2 - 5 } & $H(\mathrm{~mm})$ & $\mathrm{DP}(\mathrm{mm})$ & $B(\mathrm{~mm})$ & $W(\mathrm{~mm})$ \\
\hline 1 & 9.6 & 8.0 & 2.4 & 10.5 \\
2 & 10.3 & 8.9 & 2.5 & 10.6 \\
3 & 10.7 & 8.3 & 4.3 & 11.1 \\
4 & 11.5 & 9.3 & 8.3 & 11.8 \\
5 & 8.4 & 7.5 & 2.5 & 8.9 \\
6 & 10.0 & 7.7 & 3.0 & 10.7 \\
7 & 11.1 & 9.4 & 3.7 & 11.1 \\
8 & 11.3 & 9.2 & 4.2 & 11.5 \\
9 & 8.7 & 8.0 & 2.4 & 8.1 \\
10 & 10.1 & 7.7 & 3.8 & 10.9 \\
11 & 10.9 & 9.3 & 2.3 & 10.9 \\
12 & 11.2 & 9.0 & 5.9 & 10.6 \\
13 & 10.4 & 8.5 & 3.2 & 10.8 \\
14 & 10.1 & 8.1 & 2.6 & 10.7 \\
15 & 10.1 & 7.8 & 2.8 & 10.6 \\
16 & 10.2 & 8.4 & 3.1 & 10.6 \\
17 & 10.2 & 7.7 & 3.7 & 10.7 \\
\hline
\end{tabular}

the shape of the inserted rivet. The results are shown in Table 6 .

The maximum and minimum values measured for each of the geometrical features identified in Fig. 1 for the consolidated joint, among all the tested conditions are represented in Fig. 2.

As can be seen in the Fig. 2, $W$ and $H$ display similar values, both for maximum and minimum measurements. This is an indication that process parameters are influencing these two geometry characteristic values in similar ways. The relative influence from the process parameters on both $W$ and $H$ will be addressed later, allowing for deeper conclusions on this effect. The anchoring depth (Dp) is seen having close values to those of $H$. This promotes a bell-shaped geometry

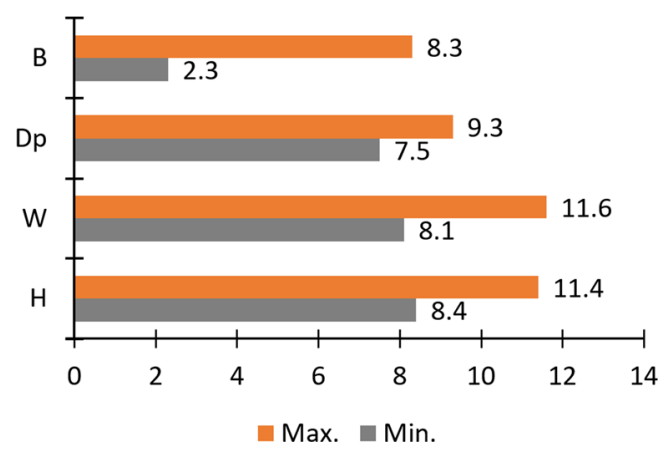

Fig. 2 Maximum and minimum values obtained from measurement in all the test conditions, of the main geometrical features in a consolidated joint produced by single-phase riveting. Values in millimeters
Table 7 Maximum process temperatures observed in the 17 testing conditions implemented

\begin{tabular}{llll}
\hline Condition & Temperature $\left({ }^{\circ} \mathrm{C}\right)$ & Condition & Temperature $\left({ }^{\circ} \mathrm{C}\right)$ \\
\hline 1 & 481 & 10 & 489 \\
2 & 482 & 11 & 472 \\
3 & 498 & 12 & 488 \\
4 & 509 & 13 & 494 \\
5 & 479 & 14 & 492 \\
6 & 504 & 15 & 498 \\
7 & 498 & 16 & 482 \\
8 & 491 & 17 & 500 \\
9 & 461 & & \\
\hline
\end{tabular}

of the plastic deformation on the tip of the rivet, which was found to promote better global mechanical performance and energy efficiency by Pina Cipriano et al. [18], in conventional friction riveting. Despite this, the fact that the maximum height of the deformed rivet tip $(B)$ is also high, indicates that in some conditions, over-deformation occurred, which can be detrimental to the performance of the joint $[18,29]$.

\subsection{Process temperature}

The maximum process temperature values registered during the production of the testing joint conditions are shown in Table 7.

From these results, it is possible to see that the parameter ranges for the present investigation produced only relatively small variations in process temperatures. The maximal amplitude observed was $48{ }^{\circ} \mathrm{C}$, between conditions 9 and 4 . The low temperature in condition 9 was produced with minimum $\mathrm{FF}$ and $\mathrm{FT}$ values $(\mathrm{FF}=2400 \mathrm{~N} ; \mathrm{FT}=2.4 \mathrm{~s}$; and $\mathrm{RS}=$ $19,500 \mathrm{rpm})$. By contrast, condition 4 was produced with $\mathrm{RS}$ and FF at maximum and with higher FT (RS = $20,000 \mathrm{rpm} ; \mathrm{FF}=2800 \mathrm{~N}$; and FT $=2600 \mathrm{~s}$ ). Despite the

Table 8 Energy input values for the joined conditions

\begin{tabular}{llll}
\hline Condition & $E_{\mathrm{M}}(\mathrm{J})$ & Condition & $E_{\mathrm{M}}(\mathrm{J})$ \\
\hline 1 & 225 & 10 & 253 \\
2 & 249 & 11 & 373 \\
3 & 472 & 12 & 529 \\
4 & 384 & 13 & 328 \\
5 & 187 & 14 & 313 \\
6 & 262 & 15 & 356 \\
7 & 423 & 16 & 345 \\
8 & 490 & 17 & 380 \\
9 & 151 & & \\
\hline
\end{tabular}




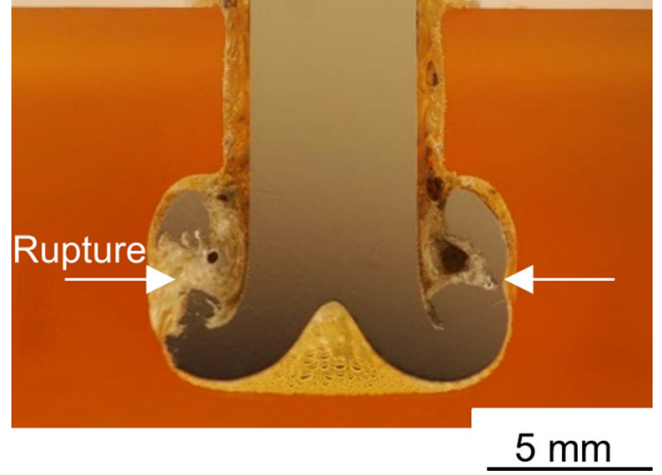

Fig. 3 Cross-section of the single-phase friction riveted joint, corresponding to the test condition 12, exhibiting over-deformation of the metallic rivet and localized degradation of the polymer

Table 9 Statistical model terms for rivet penetration $(H)$ and respective $p$-values

\begin{tabular}{ll}
\hline Term & $\begin{array}{l}p- \\
\text { value }\end{array}$ \\
\hline RS & 0.000 \\
FF & 0.000 \\
FT & 0.000 \\
RS*FT & 0.004 \\
FF*FT & 0.024 \\
\hline
\end{tabular}

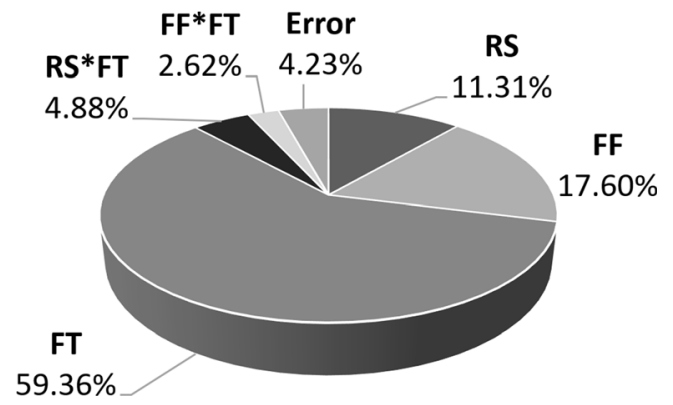

Fig. 4 Contributions of the statistical model terms for rivet penetration (H)

Fig. 5 Main effects plots for rivet penetration $(H)$ statistical model: a rotational speed, $\mathbf{b}$ friction force, and $\mathbf{c}$ friction time
Table 10 Statistical model terms for maximum width of the deformed rivet tip $(W)$ and respective $p$-values

\begin{tabular}{ll}
\hline Term & $\begin{array}{l}p \text { - } \\
\text { value }\end{array}$ \\
\hline RS & 0.001 \\
FF & 0.000 \\
FT & 0.000 \\
RS*FT & 0.012 \\
FF*FT & 0.000 \\
RS*RS & 0.007 \\
FT*FT & 0.001 \\
\hline
\end{tabular}

increase in FT, a considerably higher contribution from FF is expected. This can be confirmed by comparing condition 10 ( $\mathrm{RS}=19,500 \mathrm{rpm} ; \mathrm{FF}=2800 \mathrm{~N}$; and $\mathrm{FT}=2400 \mathrm{~s}$ ) with condition $12(\mathrm{RS}=19,500 \mathrm{rpm} ; \mathrm{FF}=2800 \mathrm{~N}$; and $\mathrm{FT}=2800 \mathrm{~s})$, where an increase of $16.7 \%$ in FT produced virtually no difference in temperature observed $\left(\sim 1^{\circ} \mathrm{C}\right)$.

\subsection{Mechanical energy input}

The results obtained mechanical energy input $\left(E_{\mathrm{M}}\right)$ are shown in Table 8.

The lowest value was obtained for condition $9\left(E_{\mathrm{M}}=151 \mathrm{~J}\right)$. The resulting joint geometry yielded the lowest value of all conditions for maximum width of the deformed rivet tip, $W=$ $8.1 \mathrm{~mm}$. This condition was produced with the lowest values of both friction force, $\mathrm{FF}=2400 \mathrm{~N}$, and friction time, $\mathrm{FT}=2.4 \mathrm{~s}$. Despite this being the lowest energy observed, the parameters used were sufficient to promote plastic deformation of the metallic rivet. Condition $5\left(E_{\mathrm{M}}=187 \mathrm{~J}\right)$ was produced with less $2.56 \%$ rotational speed, $\mathrm{RS}=19,000 \mathrm{rpm}$, additional 8.3(3) \% of friction force, $\mathrm{FF}=2600 \mathrm{~N}$, and the same friction time, $\mathrm{FT}=$ $2.4 \mathrm{~s}$. As a result, condition 5 displayed an increase of $23.8 \%$ in $E_{\mathrm{M}}$ compared with condition 9 . Hence, it is already possible to conclude that the variation of friction force had a greater impact than the decrease in rotational speed. This has also been reported in literature for conventional friction riveting [17].

Condition 12 yielded the highest value of mechanical energy input $\left(E_{\mathrm{M}}=529 \mathrm{~J}\right)$. The value was 3.5 times higher than the minimum (condition 9). Given that for condition 9 it was already possible to achieve plastic deformation, such higher energy is likely to promote what Pina Cipriano et al. [18]
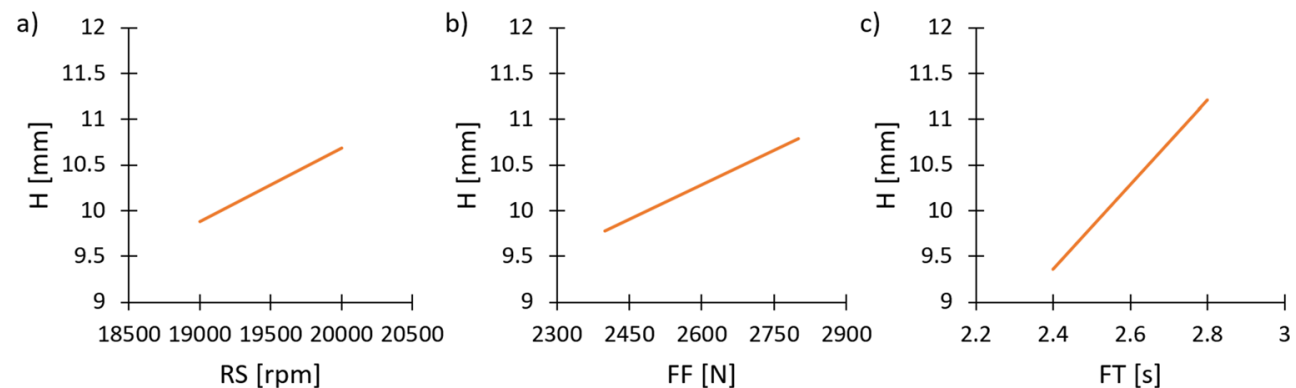


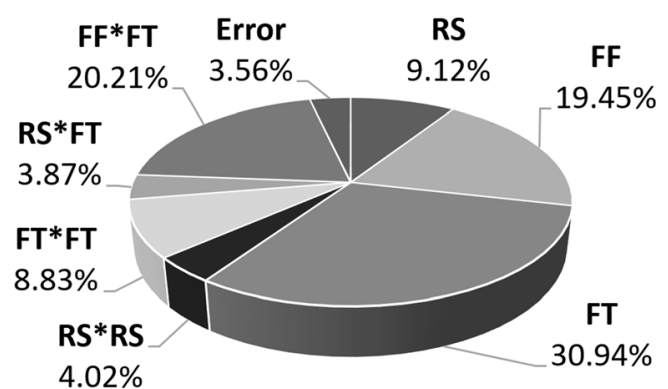

Fig. 6 Contributions of the statistical model terms for maximum width of the deformed rivet tip $(W)$

designated as over-deformation. Figure 3 confirms this assumption.

It is possible to see (indicated with arrows in the figure) where the metallic material ruptured as a result of the excessive energy applied, as found before in conventional friction riveting, by Pina Cipriano et al. [17]. This effect is attributed to the local variations in polymer viscosity, caused by the excessive heat input, promoting unsteady and abrupt rivet plastic deformation [31]. This is expected to influence negatively the global performance of the joint.

\subsection{Influence of the process parameters}

The investigated process responses of joint formation, process temperature, and mechanical energy input were statistically evaluated, one by one, based on response surface methodology, BoxBehnken design of experiments, as described in Sect. 3.5.

\subsubsection{Joint formation}

In order to assess the influence of the process parameters on joint formation, both $H$ and $W$ were considered for statistical analysis.

In the case of rivet penetration, all the three process parameters (RS, FF, FT) were found to be statistically significant. Two-way parameter interactions between FT and both RS and FF were also found to be of significance for the outcome of $H$. The $p$-values obtained from the analysis of variance (ANOVA) are shown in Table 9.

Fig. 7 Main effects plots for maximum width of the deformed rivet tip $(W)$ statistical model: a rotational speed, $\mathbf{b}$ friction force, and $\mathbf{c}$ friction time
Table 11 Statistical model terms for process temperature and respective $p$-values

\begin{tabular}{ll}
\hline Term & $\begin{array}{l}p \text { - } \\
\text { value }\end{array}$ \\
\hline RS & 0.076 \\
FF & 0.000 \\
FT & 0.295 \\
RS*FT & 0.019 \\
RS*RS & 0.026 \\
FF*FF & 0.016 \\
FT*FT & 0.018 \\
\hline
\end{tabular}

This gives an indication to the cumulative effects FT has on $H$, with the significance of the two-way interactions this process parameter takes part on.

The relative contributions of all the statistical terms is shown in Fig. 4.

The FT is by far the most influential process parameter for the rivet penetration response not only by its linear contribution but also from the two-way interactions. Pina Cipriano et al. also reported a similar contribution of FT on $H$ even for the case of the conventional five parameters friction riveting $[16,17]$. From this, the assertion that rivet penetration suffers little change from the absence of a forging force is further confirmed. In Fig. 5, it is possible to see from the main effects plots that $H$ increases with the increase of all three process parameters. As expected from the relative contributions analysis, FT is the parameter that promotes most accentuated change in $H$, as it increases at a rate of $\sim 4.6 \mathrm{~mm} / \mathrm{s}$.

Considering $W$, quadratic terms were also found to be statistically significant. The most significant terms were found to be the linear parameters (RS, FF and FT), just like for the case of $H$, but for $W$ one two-way interaction and one quadratic term were also some of the most significant (FF*FT and $\mathrm{FT} * \mathrm{FT})$. The $p$-values resulting from the ANOVA are shown in Table 10.

As expected, $W$ is a more complex response than $H$, given that is highly dependent on the evolution of plastic deformation of the metallic rivet.

The significant process terms and relative contributions are shown in Fig. 6.
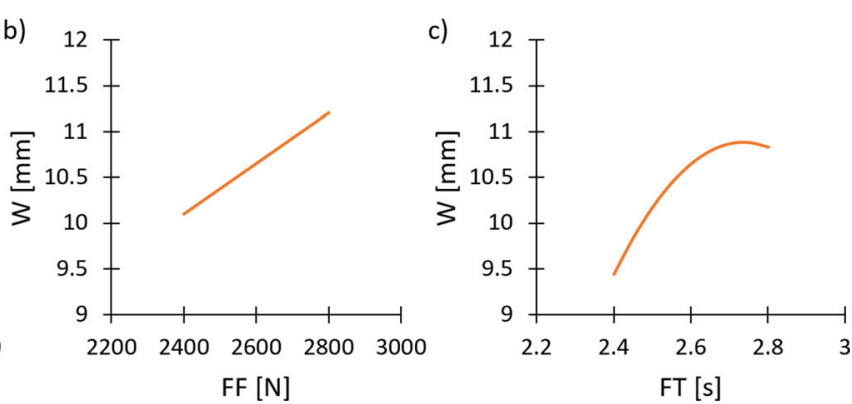


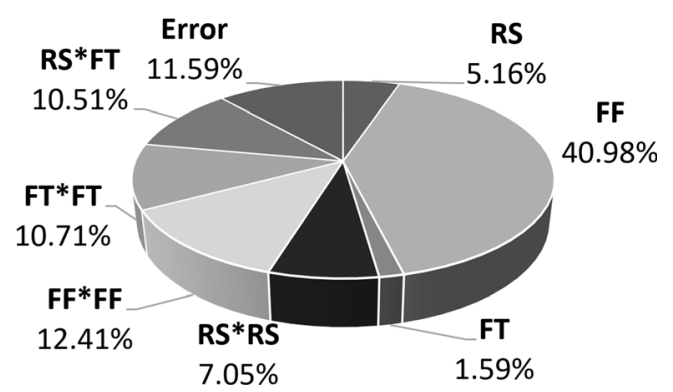

Fig. 8 Contributions of the statistical model terms for process temperature

Pina Cipriano et al. [17] reported that on the two-phase friction riveting process there were less complex parameter contributions for $W$. This can result from the fact that forging parameters could dilute or even mask some of the effects only possible to observe without the presence of such process phase. For instance, one of the major differences, the fact that here FT is the highest contributing factor and for the twophase process, FF had by far the greatest contribution [17]. This shift in contributions has to do with the fact that in their work, the process parameter interval used accounted for much lower values of FT (1.6-2.2 s), with the highest value being lower than the lowest FT used for the present work (2.4 s). With this, the contributions are not only to $W$ but also on mechanical energy input, change, with the former resulting from and the latter promoting the plastic deformation of the rivet. This will be further discussed in Sect. 4.4.3. Figure 7 shows the main effects plots for $W$. In contrast with what was seen in Fig. 5 for $H$, here both the rotational speed and friction time demonstrate higher-order effects across their ranges.

In Fig. $7 \mathrm{c}$, it is possible to see that after a FT of $\sim 2.7 \mathrm{~s}, W$ relatively stops increasing, achieving a plateau. At this point, the energy being applied to the system is high enough that the metallic material begins to rupture (see Fig. 3 as an example) and the material being plastically deformed is no longer being forced outward. Hence, no longer increasing the value of $W$.

\subsubsection{Process temperature}

The process temperature, assessed via infrared thermography, was another response investigated statistically. Although the

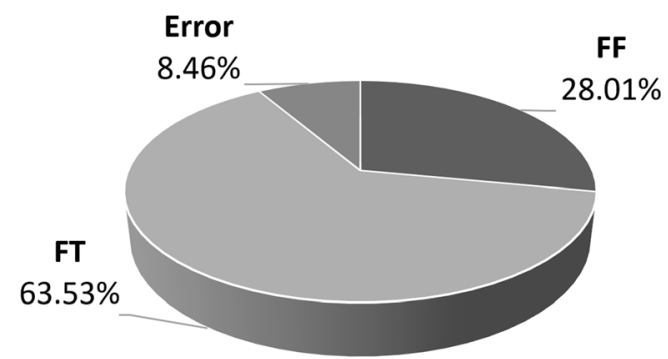

Fig. 10 Contributions of the statistical model terms for mechanical energy input $\left(E_{\mathrm{M}}\right)$

linear contributions of both RS and FT were found not to be significant, their contributions to two-way interactions or quadratic terms were. Hence, and given the consideration taken on term hierarchy, these terms were kept as part of the statistical model. The significance of the terms considered is shown through their respective $p$-values in Table 11 .

In this case, three quadratic terms, corresponding to the three linear process parameters, are significant. This entails that a nonlinear behavior of temperature response, with the variation of the process parameters, is expected for the range of values investigated. The fact that FT displays such high $p$ value can be attributed to the range of parameters used. The minimum FT (2.4 s) should appear not to be sufficiently low for a big change to be observed in the process temperature, thus becoming significant only when coupled in a two-way interaction or with its quadratic term.

The contributions to process temperate and their respective statistical terms are shown in Fig. 8.

As it was mentioned in Sect. 4.2, the statistical analysis confirms that the FT does not have a relevant linear contribution to the process temperature, accounting for just $1.69 \%$ of the total distribution. The highest contribution comes from FF. This can relate to the fact that the temperature is generated by internal shear of the molten polymer, increasing the applied pressure on that polymer tends to increase the temperature locally, as more energy is being converted by viscous dissipation $[16,17]$. Figure 9 displays the main effects plots for the influence of the process parameters on the process temperature.

From this figure, FF is the parameter promoting the highest variations on process temperature. As previously mentioned,
Fig. 9 Main effects plots for process temperature statistical model: a rotational speed, $\mathbf{b}$ friction force, and $\mathbf{c}$ friction time
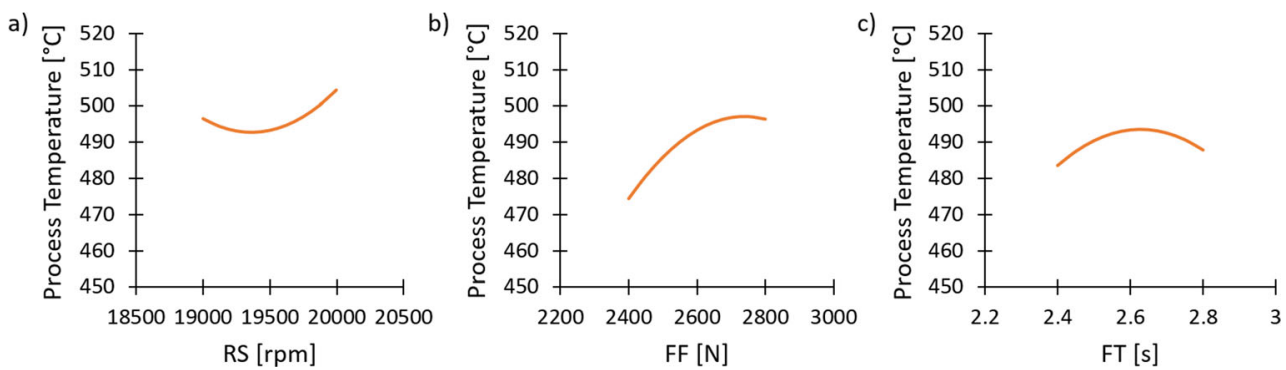


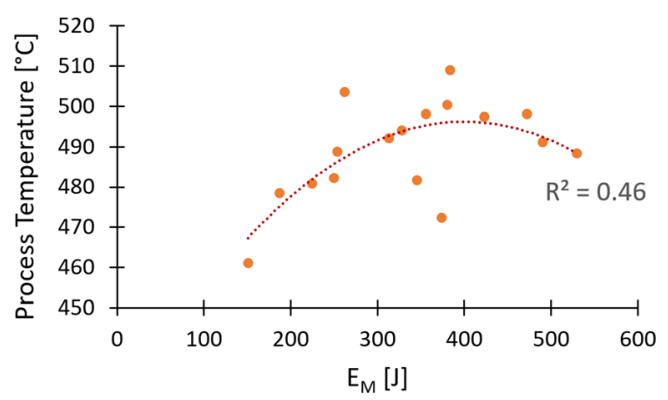

Fig. 11 Correlation between process temperature and mechanical energy input

this is the critical parameter when controlling the process temperature, given the rheological properties (thixotropic behavior) of PEI [32]. This property can lead to local gradients of polymer viscosity, resulting in abrupt changes of the metallic plastic deformation evolution [17].

\subsubsection{Mechanical energy input}

The last response statistically analyzed was mechanical energy input. From the responses investigated, mechanical energy input was the one for which the least number of terms was considered significant. No two-way interactions or quadratic terms were relevant. The terms considered were FF and FT, both with $p$-values of 0.000 . The relative contributions of these terms are seen in Fig. 10.
Table 12 Results from mechanical testing, ultimate tensile force (UTF)

\begin{tabular}{llll}
\hline Condition & UTF (N) & Condition & UTF (N) \\
\hline 1 & 6025 & 10 & 6511 \\
2 & 5413 & 11 & 6228 \\
3 & 7274 & 12 & 7467 \\
4 & 7454 & 13 & 6654 \\
5 & 7568 & 14 & 6272 \\
6 & 5630 & 15 & 6952 \\
7 & 6552 & 16 & 7041 \\
8 & 7028 & 17 & 6737 \\
9 & 7486 & & \\
\hline
\end{tabular}

It has been established in Sect. 4.1 that a minimum of considerable rivet plastic deformation had been achieved for all the investigated conditions. As such, the contribution to the increase in energy is mainly given by the increase in time of FT, with FF having a less-prominent effect. Figure 11 demonstrates the differences between increases in process temperature and in mechanical energy input.

It is possible to see, for the range of parameters investigated, the existence of an accentuated trend of increasing temperature as lower energies increase. This gradually changes over the range of energy input, even slightly stabilizing or inverting at higher energies. Pina Cipriano et al. [18] also found this initial trend of increasing process temperature with increasing energy input. In
Fig. 12 Main effects plots for mechanical energy input statistical model: a friction force and $\mathbf{b}$ friction time
Fig. 13 Correlations between joint formation and mechanical energy input: a rivet penetration and $\mathbf{b}$ maximum width of the deformed rivet tip

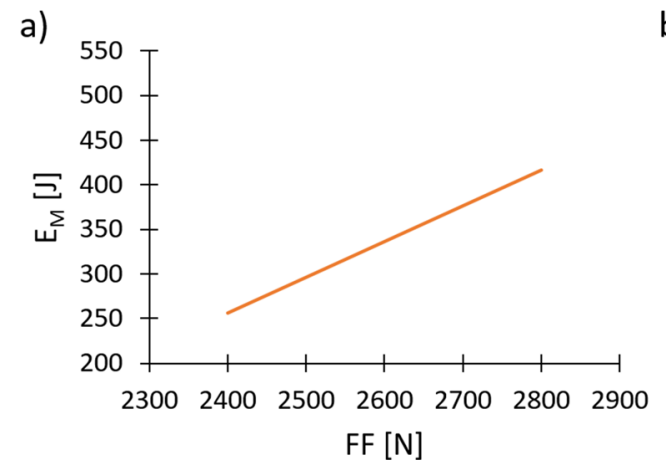

a)

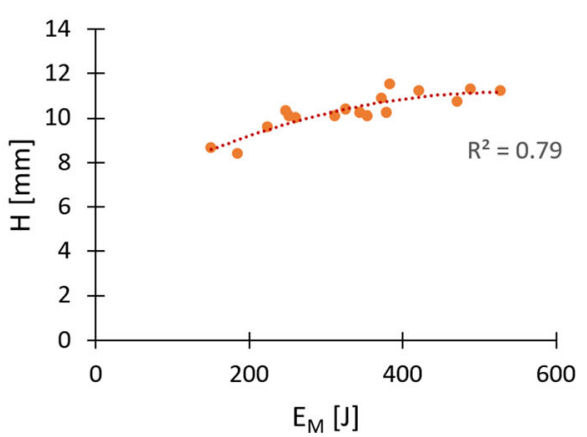

b)

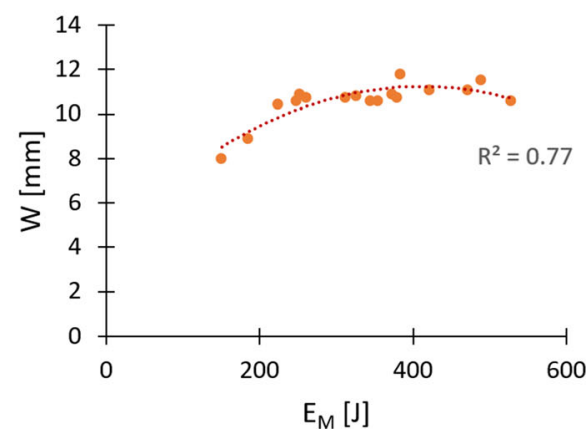

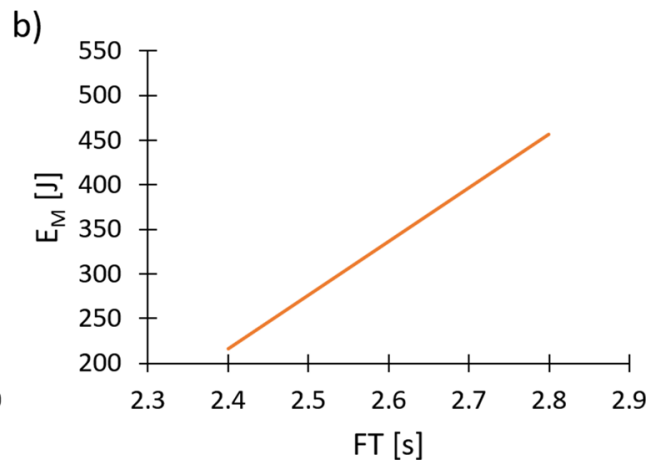


Fig. 14 Cross-sections of friction riveted joints: a conditions 2 and b 5 a)

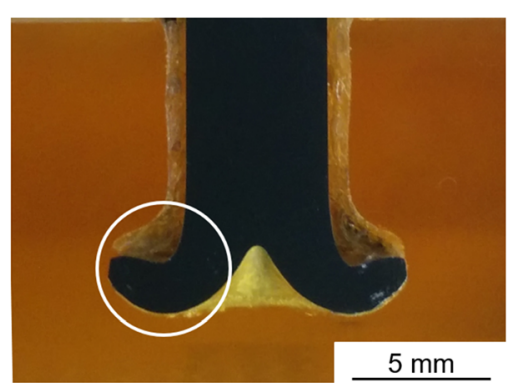

b)

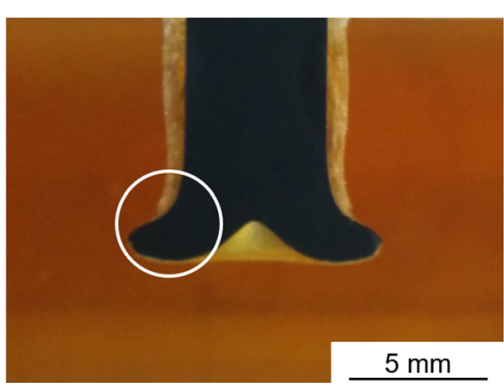

their case, the trend was valid across the energy range without great change to the correlation between the two responses. In their work, this can be explained with the considerably lower energies observed. They observed an energy input range (24 $208 \mathrm{~J})$ significantly lower than the present one (151-529 J), more so, taking into account that both frictional and deformational contributions were considered in their case.

Figure 12 shows the main effects plots for the significant parameters related to energy input.

As expected, the FT clearly promotes the highest variation of energy input across its range. This analysis shows that $E_{\mathrm{M}}$ increases at a rate of $602.5 \mathrm{~J} / \mathrm{s}$, across the range of FT, and at $0.4 \mathrm{~J} / \mathrm{N}$ across the range of $\mathrm{FF}$.

Figure 13 evaluates correlations between the energy input and joint formation, using $H$ and $W$.

Figure 13 a displays a relatively good second-degree polynomial correlation between the increase of $H$ with increasing energy input. This increase in $H$ can also explain the stabilization or even decrease in temperature with higher energy inputs seen in Fig. 11, as $H$ will result in an also higher area of polymeric material through which temperature can be dissipated. Hence, even though the energy applied to the materials is increasing, the process temperature stabilizes as more material absorbs that increasing energy. For the case of $W$ (Fig. 13b), although there is a good correlation, an increase of $W$ with increasing $E_{\mathrm{M}}$ is no longer valid. After an initial trend increasing trend for lower energies, it stabilizes after $300{ }^{\circ} \mathrm{C}$. Pina Cipriano et al. did not observe this effect, again given the lower ranges of energies they used.

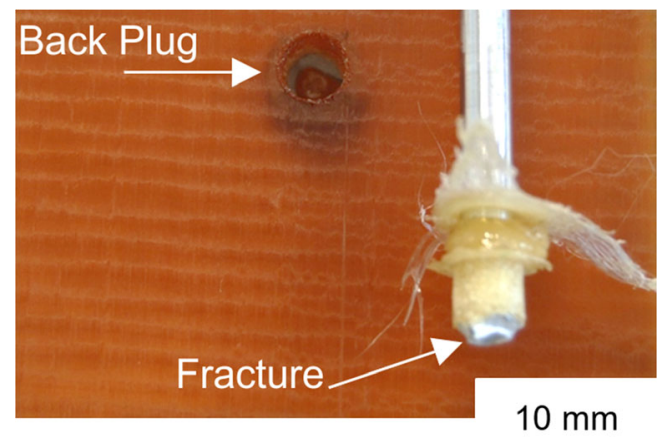

Fig. 15 Condition 2 failure after T-Pull quasi-static mechanical testing. Example of rivet pull-out with back plug failure type

\subsection{Global mechanical performance and energy efficiency}

The global mechanical performance was investigated using the methodology described in Sect. 3.6. The results obtained for ultimate tensile force (UTF) are shown in Table 12.

The minimum UTF was achieved by condition $2,5416 \mathrm{~N}$ $\left(E_{\mathrm{M}}=249 \mathrm{~J}\right)$. The condition with the highest result was condition $5\left(\mathrm{UTF}=7568 \mathrm{~N} ; E_{\mathrm{M}}=187 \mathrm{~J}\right)$. The joint formation of the two conditions is shown in Fig. 14.

Although condition 2 yielded a higher plastic deformation ( $H=10.3 \mathrm{~mm} ; W=10.6 \mathrm{~mm})$, without apparently being excessive, the UTF result clearly demonstrates that this is not a favorable joint formation performance wise. Circularly highlighted in Fig. 14 are the differences in the areas where the rivet-extended deformed material is in contact with the polymer. In condition 2 (Fig. 14a), it can be seen that there is a volume above the deformed rivet where the molten polymer was being expelled as a flash material during the process. This volume offers a lower immediate resistance to a pull-out mechanical solicitation applied to the joint, which is not the case for condition 5. This facilitates the rupture of the deformed rivet tip and consequent pull-out of the inserted rivet main body, leaving a back plug inside the polymer. This facture type is designated as rivet pull-out with back plug [18, 29]. Figure 15 shows the result of this type of fracture for Condition 2. This fracture occurs when the metal of the area between the rivet original cylindric body and the extended deformed tip, has an inferior resistance to that offered by the

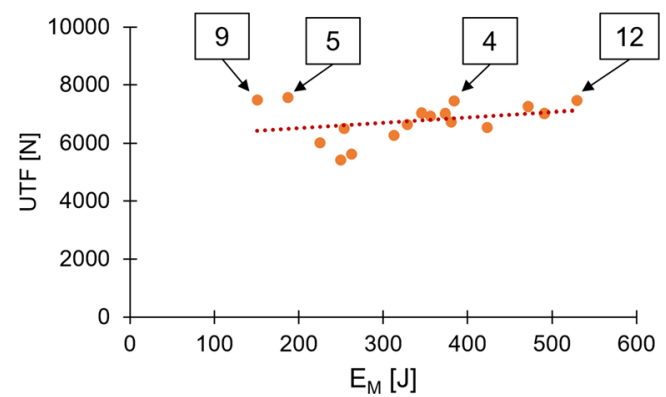

Fig. 16 Correlation between mechanical performance and mechanical energy input $\left(E_{\mathrm{M}}\right)$ 
Table 13 Energy efficiency comparison between conditions 9 and 12

\begin{tabular}{llll}
\hline Condition & $E_{\mathrm{M}}(\mathrm{J})$ & $\mathrm{UTF}(\mathrm{N})$ & EPR $(\mathrm{N} / \mathrm{J})$ \\
\hline 9 & 151 & 7486 & 49.6 \\
12 & 529 & 7457 & 14.1 \\
\hline
\end{tabular}

interaction volume of polymer above the deformed rivet tip $[18,29]$. All conditions yielded this type of fracture when subjected to the T-Pull tensile test, despite the amplitude of $2152 \mathrm{~N}$ in UTF across all conditions. This is in accordance with the findings of Pina Cipriano et al. [18], as in their investigation, the UTF for the tested conditions that yielded this type of fracture ranged from 5041 to $9362 \mathrm{~N}$.

In order to assess the energy efficiency of the joints produced, a comparison between mechanical energy input and global mechanical performance is shown in Fig. 16.

Indicated in the figure are several conditions $(4,5,9$, and 12) which achieved similar values of UTF (7454-7568 N), despite widely different values of $E_{\mathrm{M}}(151-529 \mathrm{~J})$. The two conditions defining the extremes of the energy range being condition 9 $(\mathrm{UTF}=7486 \mathrm{~N})$ and condition $12(\mathrm{UTF}=7457 \mathrm{~N})$. Table 13 gives an overview of these two conditions exploring an energyperformance ratio (EPR) concept.

As can be seen, condition 9 is considerably more efficient than condition 12, by a factor of 3.52. Figure 17 shows the joint formation of condition 9. It is characterized by a bell-shaped rivet plastic deformation, in contrast with condition 12 (Fig. 3) where over-deformation and rupture were observed. Pina Cipriano et al. have established the bell-shape type of deformation as preferable, being capable of achieving higher mechanical performances and presenting greater energy efficiency. The present results are in accordance with those findings.

Figure 12 shows how the friction time had a greater increasing effect on mechanical energy input than that of the friction force parameter. As such, after establishing the counterproductive effect excessive energy has on joint formation, the FT parameter should be minimized when possible. This will allow the production of joints without excessive rivet plastic deformation resulting from high mechanical energy input. Hence, producing more energy-efficient friction-riveted joints, based on their global mechanical performance.

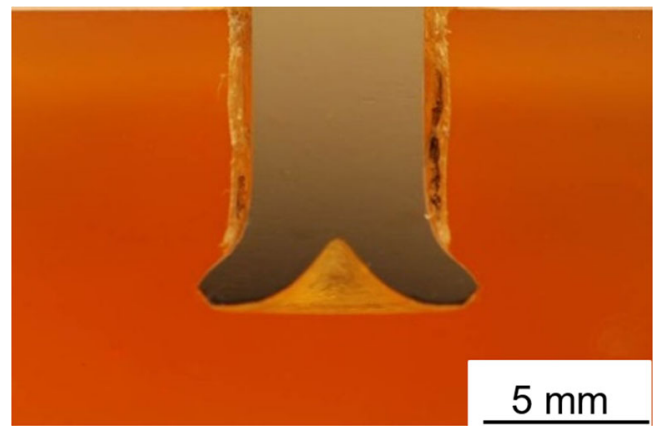

Fig. 17 Cross-section of condition 9 friction riveted joint

\section{Conclusions}

The present work explored the possibility of performing forcecontrolled time-limited friction riveting without applying a forging phase. This single-phase process variant aimed at joining dissimilar materials while greatly reducing the necessary maximum forces. A design of experiments was used to set the parameter matrix used to perform the investigated joints. The metallic rivets with $5 \mathrm{~mm}$ of diameter were successfully plastically deformed inside the PEI plates, using just three process parameters in one friction phase (rotational speed, friction force, and friction time). An amplitude of $48^{\circ} \mathrm{C}$ was observed for the maximum process temperatures registered (from 461 to $509{ }^{\circ} \mathrm{C}$ ). For the mechanical energy input, used for these joints, a wide range was observed, from 151 to $529 \mathrm{~J}$.

Rivet penetration depth, $H$ ranged from 8.4 to $11.4 \mathrm{~mm}$, which was a considerable depth. This, as seen from the statistical analysis, was mainly a result from the friction times used, as this process parameter had a contribution of $\sim 59 \%$ toward $H$. Maximum width of the rivet tip, $W$ also demonstrated significant plastic deformation, with the maximum value of $11.6 \mathrm{~mm}$ and the minimum of $8.1 \mathrm{~mm}$, coming from the original diameter of $5 \mathrm{~mm}$. In this case $(W)$, friction time also presented the highest contribution $(\sim 31 \%)$, despite the more complex distribution, with both two-way interactions $(\sim 24 \%)$ and second-order $(\sim$ $13 \%$ ) terms having statistically significant contributions.

In the case of the mechanical energy input, only the linear contributions of two process parameters: friction time and friction force, were statistically significant. Friction time presented the highest contribution, 63\%. No linear correlation was between the energy input and process temperature was valid over the investigated range of parameters, despite a proportional increase between both at lower energies $(\sim<350 \mathrm{~J})$.

The global mechanical performance of the joints was assessed by T-Pull tensile testing. The ultimate tensile force values achieved ranged from 5416 to 7568 N. The highest values corresponded to a bell-shaped deformed rivet tip. Several conditions demonstrated over-deformation, which resulted in lower than expected ultimate tensile force. All the tested conditions yielded a rivet pull-out with back plug. The energy efficiency of the tested conditions was evaluated and the conditions corresponding to the lowest values were found to be the most efficient.

From the present work, it is possible to conclude that singlephase, force-controlled, and time-limited friction riveting can be used to perform AA2024/PEI hybrid joints. A considerable global mechanical performance was achieved with relatively low mechanical energy input. Moreover, the lower range of force necessary to produce these joints allows for the application of this process in more versatile ways, demanding less from the equipment used and from the parts being joined.

Acknowledgements Open access funding provided by Aalto University. The authors would like to acknowledge the financial support provided by 
the Helmholtz Association, Germany (Grant No. VH-NG-626), the Austrian aviation program TAKE OFF, and BMVIT-Austrian Ministry for Transport, Innovation and Technology.

Open Access This article is distributed under the terms of the Creative Commons Attribution 4.0 International License (http:// creativecommons.org/licenses/by/4.0/), which permits unrestricted use, distribution, and reproduction in any medium, provided you give appropriate credit to the original author(s) and the source, provide a link to the Creative Commons license, and indicate if changes were made.

\section{References}

1. Amancio-Filho ST, Abibe AB, Dos Santos JF (2012) Joining: mechanical fastening of polymers, composites, and polymer-metal hybrid structures. In: Nicolais L, Borzacchiello A (eds) Wiley encyclopedia of composites. John Wiley \& Sons, Inc

2. Amancio-Filho ST, Dos Santos JF (2009) Joining of polymers and polymer-metal hybrid structures: recent developments and trends. Polym Eng Sci 49:1461-1476. https://doi.org/10.1002/pen.21424

3. Ghassemieh E (2011) Materials in automotive application, state of the art and prospects. New Trends Dev Automot Ind:365-394. https://doi.org/10.5772/1821

4. Baldan A (2004) Adhesively-bonded joints and repairs in metallic alloys, polymers and composite materials: adhesives, adhesion theories and surface pretreatment. J Mater Sci 39:1-49. https://doi.org/ 10.1023/B:JMSC.0000007726.58758.e4

5. Amancio-Filho ST, Blaga L-A (2018) Joining of polymer-metal hybrid structures: principles and applications. John Wiley \& Sons, Inc, Hoboken, NJ

6. Goushegir SM, dos Santos JF, Amancio-Filho ST (2015) Influence of process parameters on mechanical performance and bonding area of AA2024/carbon-fiber-reinforced poly(phenylene sulfide) friction spot single lap joints. Mater Des 83:431-442. https://doi.org/ 10.1016/j.matdes.2015.06.044

7. Abibe AB, Amancio-Filho ST, dos Santos JF, Hage E (2013) Mechanical and failure behaviour of hybrid polymer-metal staked joints. Mater Des 46:338-347. https://doi.org/10.1016/j.matdes.2012.10.043

8. Feistauer EE, Guimarães RP, Ebel T et al (2016) Ultrasonic joining: a novel direct-assembly technique for metal-composite hybrid structures. Mater Lett 170:1-4. https://doi.org/10.1016/j.matlet.2016.01.137

9. Amancio-Filho ST, dos Santos JF (2011) Henry Granjon Prize Competition 2009 winner category A: "joining and fabrication technology" friction riveting: development and analysis of a new joining technique for polymer-metal multi-material structures. Weld World 55:13-24. https://doi.org/10.1007/BF03263511

10. Proenca BC, Blaga L-A, Dos Santos JF et al (2015) Force controlled friction riveting of glass Fiber reinforced polyamide 6 and aluminum alloy 6056 hybrid joints. In: Proc. ANTEC 2015

11. Blaga L, dos Santos JF, Bancila R, Amancio-Filho ST (2015) Friction riveting (FricRiveting) as a new joining technique in GFRP lightweight bridge construction. Constr Build Mater 80: 167-179. https://doi.org/10.1016/j.conbuildmat.2015.01.001

12. Altmeyer J, Suhuddin UFH, dos Santos JF, Amancio-Filho ST (2015) Microstructure and mechanical performance of metal-composite hybrid joints produced by FricRiveting. Compos Part B Eng 81:130-140. https://doi.org/10.1016/j.compositesb.2015.06.015

13. Borba N, Afonso C, Blaga L, dos Santos J, Canto L, Amancio-Filho S (2017) On the process-related rivet microstructural evolution, material flow and mechanical properties of Ti-6Al-4V/GFRP friction-riveted joints. Materials (Basel) 10:184. https://doi.org/10.3390/ma10020184

14. Borba NZ, Blaga L, dos Santos JF, Amancio-Filho ST (2018) Directfriction riveting of polymer composite laminates for aircraft applications. Mater Lett 215:31-34. https://doi.org/10.1016/J.MATLET.2017.12.033
15. Borges MF, Amancio-Filho ST, dos Santos JF, Strohaecker TR, Mazzaferro JAE (2012) Development of computational models to predict the mechanical behavior of friction riveting joints. Comput Mater Sci 54:7-15. https://doi.org/10.1016/j.commatsci.2011.10.031

16. Amancio-Filho ST, Dos Santos JF (2016) Preliminary analytical modeling of heat input in friction riveting. In: Annual technical conference-ANTEC, conference proceedings, pp 1310-1317

17. Pina Cipriano G, Blaga L, dos Santos JF et al (2018) Fundamentals of force-controlled friction riveting: part I-joint formation and heat development. Materials (Basel):1-23. https://doi.org/10.3390/ ma11112294

18. Pina Cipriano G, Blaga L, dos Santos J, Vilaça P, Amancio-Filho S (2018) Fundamentals of force-controlled friction riveting: part IIjoint global mechanical performance and energy efficiency. Materials (Basel) 11:2489. https://doi.org/10.3390/ma11122489

19. J.R. Davis \& Associates, ASM International. Handbook Committee (1993) Aluminum and aluminum alloys. ASM International

20. U.S. Department of Defense (1998) MIL-HDBK-5H: military handbook metallic materials and elements for aerospace vehicle structures. Mil Handb:5-7 https://doi.org/http://www.knovel.com/ knovel2/Toc.jsp?BookID=754

21. Wirth JG (1986) Discovery and development of polyetherimides. In: High performance polymers: their origin and development. Springer Netherlands, Dordrecht, pp 195-205

22. Visakh PM, Thomas S (2011) Engineering and specialty thermoplastics: nylons: state of art, new challenges and opportunities. Handb Eng Spec Thermoplast 4:1-9. https://doi.org/10.1002/9781118229064.ch1

23. Professional Plastics (2011) Duratron U1000 PEI. Quadrant plastics. Retrieved from https://www.quadrantplastics.com/de/ produkte/technische-kunststoffe/temperatur-160-220-c/duratronrpei/?r=1. Accessed 19 March 2018

24. Altmeyer J, dos Santos JF, Amancio-Filho ST (2014) Effect of the friction riveting process parameters on the joint formation and performance of Ti alloy/short-fibre reinforced polyether ether ketone joints. Mater Des 60:164-176. https://doi.org/10.1016/j.matdes.2014.03.042

25. Crawford RJ, Tam Y (1981) Friction welding of plastics. J Mater Sci 16:3275-3282

26. Ma TJ, Li W, Yang SY (2009) Impact toughness and fracture analysis of linear friction welded Ti-6Al-4V alloy joints. Mater Des 30: 2128-2132. https://doi.org/10.1016/j.matdes.2008.08.029

27. Montgomery DC (2001) Design and analysis of experiments. Design 2:780 ST-design and analysis of experiments. Adva. https://doi.org/10.1198/tech.2006.s372

28. Myers RH, Montgomery DC, Anderson-Cook CM (2011) Response surface methodology: process and product optimization using designed experiments. John Wiley \& Sons

29. Rodrigues CF, Blaga LA, dos Santos JF, Canto LB, Hage E Jr, Amancio-Filho ST (2014) FricRiveting of aluminum 2024-T351 and polycarbonate: temperature evolution, microstructure and mechanical performance. J Mater Process Technol 214:2029-2039. https://doi.org/10.1016/J.JMATPROTEC.2013.12.018

30. EN-ISO 6892-1:2009 (2012) Metallic materials - tensile testingpart 1: method of test at room temperature. Eur Comm Stand

31. Amancio-Filho ST, Amancio S (2007) Friction riveting: development and analysis of a new joining technique for polymer-metal multimaterials structures. Technische Universität Hamburg-Harburg

32. Johnson RO, Teutsch EO (1983) Thermoplastic aromatic polyimide composites. Polym Compos 4:162-166. https://doi.org/10.1002/pc. 750040305

Publisher's note Springer Nature remains neutral with regard to jurisdictional claims in published maps and institutional affiliations. 